\title{
ileri yaş doğuştan çarpık ayak konservatif tedavisi
}

\section{Conservative treatment of the congenital clubfoot at advanced age}

\author{
Timur Yıldırım¹, Avni İlhan Bayhann ${ }^{1}$, Ayşegül Bursalı \\ 1S.B. Metin Sabancı Baltalimanı Kemik Hastalıkları Eğitim ve Araştırma Hastanesi, İstanbul \\ ${ }^{2}$ Ortopedi ve Travmatoloji Uzmanı, Özel Hekim
}

\begin{abstract}
İleri yaş pes ekinovarusun tedavisinde amaç, infantil dönemde olduğu gibi tabanıyla basan, ağrısız ve fonksiyonel bir ayak elde etmektir. Ancak, yaşın ilerlemesi ile birlikte kemik ve eklemler deformiteye adapte olur, ayak daha sert bir yapıya bürünür ve böylelikle, alçı ile düzeltmeye daha dirençli bir hal alır. İhmal edilmiş pes ekinovaruslu ayakların Ponseti tekniği ile tedavisi öncesi, yumuşak dokuların esnetilmesi için 5-10 dakika manipülasyon uygulanması gereklidir. Gerek manipülasyon, gerekse alçılama sırasında çocuğun sakin kalması, işlemin sağıklı yürütülmesi açısından önemlidir. Manipülasyon uygulanmış ayaklar, diz üstü alçı ile tespit edilir ve düzelme elde edilene kadar 1-2 haftalık aralarla alçılanır. Ayak ön ve orta kısım deformitelerinin alçı ile düzeltilmesi sonrası, ekin deformitesinin düzeltilmesi için aşilotomi veya aşiloplasti uygulanması gerekir. Deformitenin nüks etmemesi için, infantil dönemde olduğu gibi, Ponseti cihazı veya AFO kullanılmalıdır. Ponseti alçılama tekniği, ileri yaş pes ekinovaruslu hastaların plantigrad, esnek ve fonksiyonel bir ayak elde etme hedefine ulaşmak için uygulanabilecek, ucuz, basit ve etkili bir tedavi yöntemidir.
\end{abstract}

Anahtar sözcülkler: talipes ekinovarus, ihmal edilmiş; çarpık ayak; alçılama; Ponseti tekniği

\begin{abstract}
The main goal of the treatment of the clubfoot at advanced age is similar to infantile, which is to achieve a plantigrade, painless and functional foot. However, the bone and joints adjust to the deformity with the progression of the age; the foot gets stiffer, and thereby developes more resistance to correction by casting. In the treatment of neglected clubfeet with Ponseti technique, five to ten minutes of manipulation is mandatory for stretching the soft tissues. Either during casting or manipulation, it is important to keep the child calm for healthy intervention. Manipulated feet are retained in a long leg cast and the same procedure is repeated in 1 or 2 weeks of intervals until the deformity is corrected. Achilles tenotomy or lengthening must be applied for the correction of equinus deformity after the correction of the mid and forefoot. A Ponseti brace or AFO similar to infantile age treatments must be used for the prevention of relapses. Ponseti technique is a cheap, simple and effective option for achieving a plantigrade, flexible and functional foot in the treatment of children with clubfoot at advanced age.
\end{abstract}

Key words: talipes equinovarus, neglected; clubfoot; casting; Ponseti technique hmal edilmiş pes ekinovarus tanımı, çoğu zaman herhangi bir tedavi almamış, yetersiz tedavi almış veya başlangıç tedavisi uygun olmayan hastaları kapsar. Deformite, çocuğun yürümeye başlaması ile ağırlaşır. İleri yaş hastaların ayaklarında, tedavisiz geçen zamana bağlı olarak gelişen adaptif değişiklikler, tedavinin yenidoğan döneminden bir takım farklıklar içermesine neden olur. İleri yaş veya nüks etmiş pes ekinovarusun tedavisinde amaç; infantil dönemde olduğu gibi tabanıyla basan (plantigrad), hareketli, ağrısız, normal görünümlü ve ayakkabı modifikasyonu gerektirmeyen bir ayak elde etmektir. ${ }^{[1]} \mathrm{Bu}$ hasta grubunda plantigrad ayak hedefine ulaşılabilse de, ayağın yenidoğan dönemine göre daha sert olmasından dolayı, esnek ve hareketli bir ayak elde etme hedefine ulaşmak zordur. Literatürde, ileri yaş pes ekinovarusun tedavisi için; alçılama, yumuşak doku prosedürleri, osteotomi ve/veya kemik eksizyonunu içeren teknikler, eksternal fiksatör uygulamaları gibi seçenekler sunulmaktadır. Ancak, uzun vadede ağrısız ve fonksiyonel bir ayak elde etmek için uygulanacak tedavi yöntemiyle, daha fazla kapsül içi skar oluşumu veya kemik füzyonuna neden olunmamasına özen gösterilmelidir. Bir diğer önemli nokta da, ayak uzunluğunun olabildiğince korunmasını

- Illetişim adresi: Op. Dr. Timur Yıldırım, S.B. Metin Sabancı Baltalimanı Kemik Hastalıkları Eğitim ve Araştırma Hastanesi, Rumeli Hisarı Caddesi, No: 62, Sarıyer, İstanbul Tel: 0505 - 6234824 e-posta: drtimur@hotmail.com

- Geliş tarihi: 25 Mayıs 2015 Kabul tarihi: 25 Mayıs 2015 
sağlayacak yöntemleri kullanmaktır. Bu derlemedeki amacımız, Ponseti yöntemi ile ileri yaş pes ekinovarus deformitesinin tedavisinin incelenmesidir.

\section{İleri Yaş Pes Ekinovarus Deformitesinin Yenidoğan Döneminden Gösterdiği Farklılıklar}

İlk göze çarpan bulgu, ayağın daha sert olmasıdır. ${ }^{[2]}$ Büyüme ve yüklenmenin etkisiyle, kapsüler dokular hipertrofiye olur. Daha önceden cerrahi müdahale geçiren çocuklarda, kalın skar formasyonu oluşumu da mevcuttur.

İkinci olarak gözlenen önemli bir farklılık da, tarsal kemiklerin yenidoğan dönemine göre daha olgunlaşmış olmasıdır. İnfantil dönemde, ayağın kemik yapısı büyük oranda kıkırdak dokudan oluşur ve bu yaşlarda deformitenin düzelmesi, ileri yaşlara göre daha fizyolojik bir strese maruz kalan kıkırdak yapıdaki tarsal kemiklerin morfolojik değişiklikleri ile olur. ${ }^{[2]}$

Üçüncü bir farklılık, yüklenme sonucunda gelişen trofik değişikliklerdir (Şekil 1). Ciltte kalloziteler gözlenebileceği gibi, yüklenmenin olduğu kemikte hipertrofi ve tam tersi yönde, yüklenmenin azaldığı bölümlerde hipoplazi gözlenebilir.

Dördüncü olarak, kas ve tendonlar deformiteye adapte olabilir. Örneğin, ihmal edilmiş pes ekinovarus deformitesi olan ayaklarda, abduktor hallusis kası ayak ön kısmının supinasyonu ve kavusun devamlılığı için kuwvetli bir güç oluşturmaktadır. Ayrıca tibialis anteriorun güçlü ve hipertrofik olduğu; bunun tersi olarak, antagonistleri olan peroneal kasların uzamış ve zayıf olduğu gözlenir.
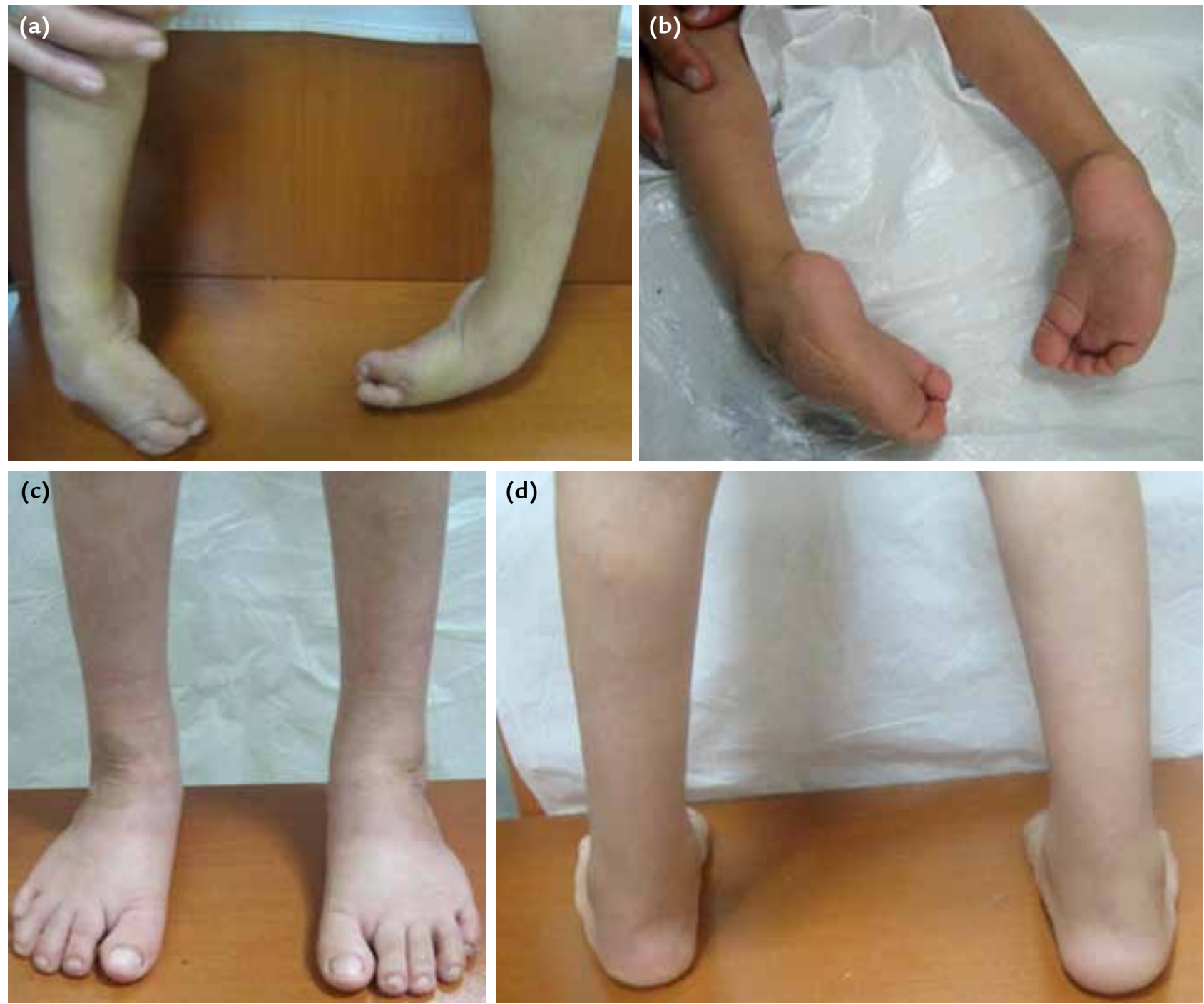

Şekil 1. Üç yıl dört aylık erkek çocuğa ait bilateral ihmal edilmiş pes ekinovarus. Alçılama öncesi ayakların önden (a) ve arkadan (b) görünüşleri. Altı alçı ve aşilotomi sonrası 4. yıl takip fotoğrafları: basarken önden (c) ve arkadan görünüş (d). 


\section{ILERI YAŞ PES EKINOVARUSTA ALÇILAMA TEKNiĞi}

Ponseti tekniğinde alçı, manipülasyonla kazanılan düzeltmenin korunması için uygulanır. Bu yaş civarında yapılan alçılama, infantil döneme göre bazı farklılıklar içermektedir. Klasik Ponseti tekniğinde, ortalama iki dakika germe önerilmektedir. Lourenço ve Morcuende, ileri yaştaki çocuklarda bu sürenin 5-10 dakika arasında olması gerektiğini bildirmektedir. Gerek manipülasyon gerekse alçılama sırasında çocuğun sakin kalması, işlemin sağlıklı yürümesi açısından önemlidir. Sakinleşme, manipülasyon veya alçılama sırasında bebeğin beslenmesi, emzik kullandırılması veya oyuncakla oyalanması ile sağlanabilir. Ajitasyon sırasında veya zorlayıcı manipülasyonlarla uygulanan alçılamalar, doku içi kanamalara yol açarak, işlemin sert ayakla sonuçlanmasına neden olur. Lourenço ve Morcuende, yumuşak dokuların ve kıkırdak-kemik yapıların yeniden şekillenmesine olanak sağlamak için, alçılamanın iki hafta ara ile yapılmasını önermektelerse de, literatürde genellikle haftalık alçılama önerilmektedir. İleri yaş pes ekinovarus tedavisinde de, yenidoğan dönemi tedavisinde olduğu gibi, klasik Ponseti alçılama tekniği uygulanır. Diz $90^{\circ}$ fleksiyonda uzun bacak alçı uygulanır. Adaptif değişikliklerden dolayı, yenidoğan döneminden farklı olarak, son alçıda $70^{\circ}$ abduksiyon yerine $30-40^{\circ}$ abduksiyon amaçlanmaktadır. Lourenço ve Morcuende, ileri yaş çocuklarda Ponseti tekniği ile ayak önü ve ortası deformitelerin ayak ardına göre daha iyi düzeltilebildiğinden ve bu nedenle, bazı olgularda posterior gevşetmenin uygulanabileceğinden bahsetmişlerdir. Beş yaşına kadar olan çocuklarda, ekin deformitesinin düzeltilmesi için aşilotomi uygulanır. Aşilotomi dokuz yaşına kadar uygulanabilse de, beş yaşından daha büyük çocuklarda geniş insizyonlardan kaçınılarak yapılacak aşiloplasti önerilmektedir. ${ }^{[1]}$

İleri yaş pes ekinovarusun Ponseti tekniği ile tedavisi ile ilgili diğer konu, bu yaş grubunda Ponseti cihazına olan uyum zorluğudur. Yazarlar, bu yaş grubunda Ponseti ayakkabısı yerine AFO'nun (Ankle Foot Orthesis) 12 ay boyunca kullanılabileceğinden bahsetmektedirler. ${ }^{[3]}$ Kimi yazarlar da, Ponseti cihazının yalnız gece kullanımını önermektedir. ${ }^{[4]}$ Bu konuda bizim önerimiz, nüksten korunmak için, hastaların en az bir yıl süreyle geceleri Ponseti cihazı, gündüzleri ise AFO kullanmaları için ısrarcı olunması yönündedir.

Ponseti, kendi tedavisini tanımladığı hasta grubunda altı ay ve daha genç olan olguları kullanmasına rağmen, bu tedavi yönteminin kaç yaşa kadar kullanılabileceğinden bahsetmemiştir. Illerleyen yıllarda, birçok farklı ülkeden ileri yaş Ponseti tedavisinin uygulanması ile ilgili yayınlar literatürde yerini almıştır (Tablo 1).

Tablo 1. İleri yaş pes ekinovarusun Ponseti yöntemi ile tedavi sonuçları

\begin{tabular}{|c|c|c|c|c|c|c|c|c|}
\hline & $\begin{array}{l}\text { Ayak } \\
\text { sayısı }\end{array}$ & $\begin{array}{l}\text { Ortalama } \\
\text { yaş (yıl) }\end{array}$ & $\begin{array}{l}\text { Ortalama } \\
\text { alçı sayısı }\end{array}$ & $\begin{array}{l}\text { Ortalama } \\
\text { alçılama } \\
\text { aralıkları }\end{array}$ & $\begin{array}{l}\text { Nüks için yapılan cerrahi } \\
\text { müdahale }\end{array}$ & $\begin{array}{l}\text { Ortalama } \\
\text { takip } \\
\text { süresi (yıl) }\end{array}$ & $\begin{array}{c}\text { Ortalama } \\
\text { dorsifleksiyon }\end{array}$ & $\begin{array}{c}\text { İyi } \\
\text { sonuç }\end{array}$ \\
\hline $\begin{array}{l}\text { Lourenço ve } \\
\text { Morcuende }^{[3]}\end{array}$ & 24 & 3,9 & 9 & 2 hafta & $\begin{array}{l}7 \text { rekürrent PAT } \\
8 \text { PG }\end{array}$ & 3,1 & $5^{\circ}$ & $\% 66,6$ \\
\hline $\begin{array}{l}\text { Nogueira ve } \\
\text { arkadaşları }\end{array}$ & 83 & 5 & 4 & 1 hafta & $\begin{array}{l}1 \text { PMG, } \\
5 \text { ATT, } \\
3 \text { ATT+LKK+PF+AU } 2 A T T+A U\end{array}$ & 3,7 & $9^{\circ}$ & $\% 86$ \\
\hline $\begin{array}{l}\text { Faizan ve } \\
\text { arkadaşları }^{[11]}\end{array}$ & 28 & 2,7 & 8 & 1 hafta & $\begin{array}{l}1 \mathrm{ATT} \\
1 \mathrm{AU}\end{array}$ & 2,7 & $16^{\circ}$ & $\% 92,8$ \\
\hline $\begin{array}{l}\text { Verma ve } \\
\text { arkadaşları }^{[10]}\end{array}$ & 55 & 2 & 10 & 1 hafta & $\begin{array}{l}4 \mathrm{ATT} \\
3 \mathrm{AU} \\
1 \mathrm{PG}\end{array}$ & 2,5 & $11,9^{\circ}$ & $\% 89,1$ \\
\hline $\begin{array}{l}\text { Yağmurlu ve } \\
\text { arkadaşları }^{[12]}\end{array}$ & 31 & 1,75 & 6 & 1 hafta & $?$ & 3,5 & ? & $\% 87$ \\
\hline $\begin{array}{l}\text { Spiegel ve } \\
\text { arkadaşlarl[ }{ }^{8]}\end{array}$ & 260 & 1,9 & 7 & 1 hafta & $?$ & ? & $12,4^{\circ}$ & $\% 94$ \\
\hline Khan ve Kumar[9] & 25 & 8,9 & 12,1 & 1 hafta & $\begin{array}{l}4 \text { PMG, } \\
1 \text { PMG+LKK }\end{array}$ & 4,7 & $7^{\circ}$ & $\% 85,7$ \\
\hline $\begin{array}{l}\text { Banskota ve } \\
\text { arkadaşları }^{[13]}\end{array}$ & 55 & 7,4 & 9,5 & 1 hafta & $\begin{array}{l}4 \mathrm{AU} \\
4 \mathrm{PG} \\
1 \mathrm{PMG}\end{array}$ & 2,6 & $9^{\circ}$ & $\% 86$ \\
\hline
\end{tabular}

PAT, perkütan Aşil tenotomi; PG, posterior gevşetme; PMG, posteromediyal gevşetme; DF, dorsifleksiyon; ATT, anterior tibialis tendon transferi; LKK, lateral kolon kısaltma; PF, plantar fasyotomi; AU, Aşil uzatma.

*Daha önceden posteromediyal gevşetme yapılmış olgu. 
Ülkemizden Göksan ve arkadaşları, Ponseti tekniği ile tedavi ettikleri bir yaş altı 134 hastalık olgu serisinde \%31 oranında nüks gördüklerini, bu hastaların tekrar alçılanmaları sonucunda yeniden nüksün 18 ayakta olduğunu, bu olguları tibialis anterior tendon transferi ile tedavi ettiklerini bildirmişlerdir. Kırk altı aylık bir takiple, ayakların \%97'sinde yumuşak doku gevşetmesi yapılmaksızın deformite düzeltilmesi sağlanmıştır. Nüksün, Ponseti cihazına uyumlu hastaların \%3'ünde, uyumsuz olanların ise \%68'inde görüldüğünü bildirmişlerdir. ${ }^{[5]}$ Alves ve arkadaşlarının 102 ayağı içeren olgu serisinde, altı ay ila 2,5 yaş arasındaki olguların, altı aydan küçük olan çocuklarda olduğu gibi tedaviye iyi cevap verdiği gözlenmiştir. Hiçbir olguda posteromediyal gevşetme gerekmemiştir. ${ }^{[6]}$ Hegazy ve arkadaşlarının, daha önce başka bir merkezde Ponseti yöntemi uygulanmış ve başarısız olmuş, yaşları 4-13 ay arasında olguları içeren serisinde, 32 ayaktan yalnız birine posteromediyal gevşetme gerekmiştir. ${ }^{[7]}$ Bir-altı yaş arasında 260 ihmal edilmiş pes ekinovarus deformiteli ayağın tedavi sonuçlarının değerlendirildiği makalede, Spiegel ve arkadaşları, bunların \%14'ünün yumuşak doku gevşetmesine ihtiyacı olduğunu bildirmişlerdir. Ayrıca, alçı sayısında ve deformitenin düzeltilmesinin sağlanmasında çocuğun yaşının etkili olmadı̆̆ını belirtmişlerdir. ${ }^{[8]}$ Lourenço ve Morcuende'nin, ortalama takip süresi bir yıl olan, daha geniş yaş aralıklı olgu serisinde (1,5-9 yaş), 24 ihmal edilmiş pes ekinovarus olgusu incelenmiştir. On beş olguda ekin deformitesi tekrarı nedeni ile düzeltme gerekmiş, yedi olguda aşil tenotomisi tekrarlanmış, sekiz olguda posterior gevşetme yapılmıştır. Yirmi dört hastanın 16'sı iyi sonuç olarak bildirilmiştir. ${ }^{[3]}$ Khan ve Kumar'ın ileriye dönük olarak en az dört yıl takip ettiği, yedi yaşından büyük 25 ayağı içeren serisinde; 19 ayak iyi sonuçlanmış, altı ayakta ( $\% 24$ ) nüks baş göstermiş ve posteromediyal gevşetme yapılmıştır. ${ }^{[9]}$ Yaş sınııını en ileri götüren çok merkezli bir çalışma, Nogueira ve arkadaşlarının primer posteromediyal gevşetmeden sonraki nükslerin tedavisini yaptıkları çalışmadır. Ortalama yaşı beş olan (yedi ay ila 14 yaş) 83 ayak ortalama 45 ay takip edilmiş, bu ayakların 71'i (\%86) plantigrad olarak sonuçlanmıştır. Bir ayakta, 10 alçılama sonrasında subtalar varusta düzelme saptanamamış, bu hastanın subtalar gevşetmesi sırasında eklemde sinostoz olduğu gözlenmiştir. Tüm hastalarda 12 nüks gözlenmiş ve bunların altısına cerrahi müdahale (tibialis anterior tendon transferi) ve üçüne de lateral kolon kısaltma, plantar fasyotomi ve Aşil tendon uzatma gerekmiştir. Başarı sonucu ile yaş arasında korelasyon bulunamamıştır. [4] Ponseti yöntemi ile alçılama, bu yaş grubunda biraz daha fazla cerrahi müdahale gerektirmektedir. Spiegel ve arkadaşlarının, yaşları 1-6 arasında değişen toplam 260 ayaklık serisinde, cerrahi girişim olarak hastaların büyük bir kısmında perkütan aşilotomi yapılması yeterli olmuş (\%83), sekiz ayakta (\%3) açık Aşil uzatma, 21 ayakta (\%8) posterior gevşetme ve 16 ayakta (\%6) posteromediyal gevşetme gerekmiştir. Geçmişte bu yaş grubunun tedavisi için uygulanan cerrahi girişimlerin büyüklügüü dikkate alınırsa, Ponseti tekniği sayesinde cerrahi ihtiyacındaki azalma miktarı daha açık ortaya çıkmaktadır.

Yaşın ilerlemesiyle birlikte, kemik yapılarda oluşan morfolojik değişiklikler tedaviyi zorlaştırdığı gibi, tedavi sonrası fonksiyonel sonuçları da etkilemektedir. Bunun en belirgin örneği, ayak bileği dorsifleksiyonundaki azalma ile kendini göstermektedir. Verma ve arkadaşlarının yaptığı çalışmada, tedaviye başlangıç yaşı 12-24 ay arası olan pes ekinovaruslu olguların Ponseti yöntemi ile tedavisi sonucunda ortalama $24,45^{\circ}$ (aralık, $0-50^{\circ}$ ) dorsifleksiyon elde edilirken, $24-36$ ay arası olan olgularda $5,78^{\circ}$ (aralık, $0-20^{\circ}$ ) dorsifleksiyon elde edilmiştir. ${ }^{[10]}$

Illeri yaş grubu pes ekinovaruslu hastaların Ponseti yöntemi ile tedavisi sonrası nükslerinden, kalın ligamentöz yapılar ve kısalmış tibialis posterior tendonunun sorumlu olabileceği düşünülmektedir. Bu nedenle, perkütan aşilotomi yapılacağı zaman, eş zamanlı olarak tibialis posterior tendonun mini-insizyon gevşetmesi ve tibialis anterior tendonunun lateral kuneiforma transferi önerilmektedir. ${ }^{[9]}$ Verma ve arkadaşları da, rekürrenslerin önlenmesi için; özellikle üç yaşından büyük, ayakları daha sert, takiplerine düzgün gelemeyecek sosyo-ekonomik düzeyde olan ve Ponseti cihazına uyumu düşük olan olgularda, tibialis anterior tendonunun transferinin erken dönemde yapılmasını önermektedir. ${ }^{[10]}$

Geçmişte geniş yumuşak doku prosedürlerinden elde edilen tecrübeler, kısa vadede düzgün görünen ayakların birçoğunun ileri dönemde sert ve ağrılı hale geldiklerini göstermektedir. Ponseti yöntemi; her yaş grubundaki pes ekinovaruslu hastaların (hatta cerrahi sekellerin tedavisinde) uzun vadeli tedavi hedefinde amaçlanan, plantigrad, esnek ve fonksiyonel bir ayak elde etmek için uygulanabilecek ucuz, basit ve etkili bir tedavi yöntemidir.

\section{KAYNAKLAR}

1. Ponseti IV. Congenital Clubfoot: Fundamentals of Treatment, 2nd ed. New York: Oxford University Press; 2008.

2. van Bosse HJ. Treatment of the neglected and relapsed clubfoot. Clin Pediatr Med Surg 2013;30(4):513-30. CrossRef

3. Lourenço AF, Morcuende JA. Correction of neglected idiopathic club foot by the Ponseti method. J Bone Joint Surg $\mathrm{Br} 2007 ; 89(3): 378-81$. 
4. Nogueira MP, Ey Batlle AM, Alves CG. Is it possible to treat recurrent clubfoot with the Ponseti technique after posteromedial release?: a preliminary study. Clin Orthop Relat Res 2009;467(5):1298-305. CrossRef

5. Göksan SB, Bursali A, Bilgili F, Sivacioğlu S, Ayanoğlu S. Ponseti technique for the correction of idiopathic clubfeet presenting up to 1 year of age. A preliminary study in children with untreated or complex deformities. Arch Orthop Trauma Surg 2006;126(1):15-21.

6. Alves C, Escalda C, Fernandes P, Tavares D, Neves MC. Ponseti method: does age at the beginning of treatment make a difference? Clin Orthop Relat Res 2009;467(5):1271-7. CrossRef

7. Hegazy M, Nasef NM, Abdel-Ghani H. Results of treatment of idiopathic clubfoot in older infants using the Ponseti method: a preliminary report. J Pediatr Orthop B 2009;18(2):76-8. CrossRef

8. Spiegel DA, Shrestha OP, Sitoula P, Rajbhandary T, Bijukachhe B, Banskota AK. Ponseti method for untreated idiopathic clubfeet in Nepalese patients from 1 to 6 years of age. Clin Orthop Relat Res 2009;467(5):1164-70. CrossRef
9. Khan SA, Kumar A. Ponseti's manipulation in neglected clubfoot in children more than 7 years of age: a prospective evaluation of 25 feet with long-term follow-up. J Pediatr Orthop B 2010;19(5):385-9. CrossRef

10. Verma A, Mehtani A, Sural S, Maini L, Gautam VK, Basran SS, Arora S. Management of idiopathic clubfoot in toddlers by Ponseti's method. J Pediatr Orthop B 2012;21(1):79-84. CrossRef

11. Faizan M, Jilani LZ, Abbas M, Zahid M, Asif N. Management of Idiopathic Clubfoot by Ponseti Technique in Children Presenting After One Year of Age. J Foot Ankle Surg 2014;pii:S1067-2516(14)00224-5. CrossRef

12. Yagmurlu MF, Ermis MN, Akdeniz HE, Kesin E, Karakas ES. Ponseti management of clubfoot after walking age. Pediatr Int 2011;53(1):85-9. CrossRef

13. Banskota B, Banskota AK, Regmi R, Rajbhandary $T$, Shrestha OP, Spiegel DA. The Ponseti method in the treatment of children with idiopathic clubfoot presenting between five and ten years of age. Bone Joint J 2013;95-B(12):1721-5. CrossRef 